Affect Check Averages

\section{A Study of the Toronto}

\section{Restaurant Market}

by Alex M. Susskind and

Edwin K. Chan
Specific restaurant attributes can boost check averages and set a restaurant apart

from competitors in the consumer's estimation.

\footnotetext{
${ }^{1}$ The market share for meal replacement may be as high as 13 percent. See: Dick Papiernik, "Takeout or Lose Out," Nation's Restaurant News, Vol. 33, No. 13 (March 29, 1999), pp. S7-S8.
}

ull-service restaurants are under more pressure than ever, in part because the restaurant business has seen strong growth in the home-mealreplacement concept in recent years. ${ }^{1}$ Given the tumultuous competition in the restaurant business, we examined the underlying determinants or drivers of a successful full-service restaurant operation. In particular, we wanted to discover what restaurant attributes improve customers' ratings of a restaurant and, more to the point, boosted check averages.

Alex M. Susskind, Ph.D., is an assistant professor of food and beverage management at Cornell University's School of Hotel Administration "ams76@cornell.edu».Edwin K. Chan, who holds a Master of Management in Hospitality $(M M H)$ degree from Cornell University, is restaurant director of 44 at the Royalton in New York City "echan@royalton.schragerhotels.com». (C) 2000, Cornell University 
This investigation focused on three specific questions: (1) What restaurant features matter the most to consumers in their dining experiences?, (2) What does it take to be the best in consumers' eyes?, and (3) To what extent do high consumer ratings predict a high check average? To answer those questions we present a multi-stage analysis of the relationships among restaurants' operational characteristics and amenities and the consumers' perceptions of restaurant quality, and, in turn, the relationship between consumers' perceptions of their restaurant experience and operators' reports regarding their check averages.

\section{Toronto Restaurant Scene}

We begin by describing Toronto's restaurant market, where we conducted this investigation, and discussing the study's methodology. We selected Toronto for two main reasons. First, Toronto is a large metropolitan area with a diverse, multiethnic population. As a consequence of Toronto's demographic profile, the city's dining scene consists of many different types of cuisine, and it features a blend of chain and independent operators-a pattern consistent with the city's unofficial motto, "diversity is our strength."2 Second, at the time of this investigation Toronto's restaurant industry was robust and exhibiting a strong period of growth, as reported by the Canadian Restaurant and Foodservice Association. ${ }^{3}$

To conduct our analyses we looked for reliable sources of both secondary and primary data.

Through an extensive search pro-

\footnotetext{
${ }^{2}$ Zagat Survey 1999 Toronto Restaurants, ed. Vallery Hyduk and Sheila Swerling-Puritt (New York: Zagat Survey, 1999).

${ }^{3}$ Carolyn Cooper, "Blue Skies Ahead-1998 Hospitality Market Report," Foodservice and Hospitality (Canada), Vol.31, No. 9 (November 1998), pp. 41-47; and Foodservice Facts-1998, (Toronto: Canadian Restaurant and Foodservice, 1998).
}

cess, we discovered readily available consumer-provided secondary data (through the Zagat Survey) ${ }^{4}$ and restaurant-provided secondary data (through Toronto Life magazine). From the winter 1998 issue of Toronto Life, which featured a collection of 90 Toronto restaurant menus, we drew pricing and basic operational information for each establishment, such as the style of cuisine, appetizers and entrées offered, prices, and hours of operation. ${ }^{5}$ The 1999 Zagat Survey offered information on 70 of the 90 restaurants listed in Toronto Life. Based on consumers' voluntary reports, the Zagat Survey provided ratings for each restaurant's food, service and décor, and style of cuisine, along with estimated price points and a notation on a "top-40 rating," if applicable. Finally, we contacted the managers in the restaurants listed in both Toronto Life and the Zagat Survey to find out their average check, restaurant volume, and restaurant size. Sixty-three of the 70 restaurants we contacted were willing to provide us with the requested information, yielding a response rate for the telephone survey of approximately 90 percent.

The restaurants we examined represented 23 different styles of cuisine out of the 54 possible categories contained in the Toronto Zagat Survey. Ethnic foods were prominent among the sample, consistent with reported food trends in the Toronto dining scene. ${ }^{6}$ Specifically, Italian restaurants were the most prominent, with 15 listings in several categories, followed by French restaurants (e.g., French,

\footnotetext{
${ }^{4}$ Zagat Survey, loc. cit.

5 “Menu Directory," Toronto Life, Vol. 32, No. 18 (1998), "www.torontolife.com/menudirectory/ leftnav_md.html».

${ }^{6}$ See: Cynthia David, "Crossing Cultures," Foodservice and Hospitality (Canada), Vol.30, No. 11 (January 1998), pp. 20-26; and Cynthia David, "Morning Rush," Foodservice and Hospitality (Canada), Vol. 31, No. 5 (July 1998), pp. 22-24.
}

French bistro, or new French). While the number of menu items offered by each restaurant differed widely, the average number of appetizers offered was 12 and the mean number of entrées was $15 .^{7}$

Top-quality restaurants. The restaurants we examined included nine of the restaurants in the Zagat organization's top 40 . The average Zagat Survey scores for the 63 restaurants in our survey (all out of a possible 30 points) were 21 for food, 18 for décor, and 19 for service. Thus, these data indicate that in general most establishments in our sample offered relatively high food quality, a pleasing décor, and good service. The greatest variation rested with scores for décor, which ranged from a low of 3 to a high of 27.

Strong check averages. The Zagat organization reported that the average dinner check for the restaurants in our sample was $\$ 42.27$, with a range of $\$ 18.00$ to $\$ 68.00$ and a standard deviation of $\$ 11.40$. $^{8}$ Average checks reported by the restaurant managers themselves were largely consistent with Zagat's data. The managers reported an average dinner check of $\$ 44.05$, with a range of $\$ 15.50$ to $\$ 100.00$ and a standard deviation of $\$ 14.93$. The correlation between the average checks reported by the restaurant operators and those reported by Zagat was $r=.78$, indicating a strong level of agreement between the two figures. The dinner-check averages put our data set well above the reported check average of $\$ 19.90$ for the fine-dining category that was reported by Canadian Restaurant and Foodservice Association. ${ }^{9}$ While the Zagat Survey is based on a sufficiently large sample of diners, we believe that the opera-

\footnotetext{
${ }^{7}$ The standard deviation for appetizers was 6.3 items and for entrées, 8.5 items.

${ }^{8}$ Figures given are Canadian dollars.

${ }^{9}$ See: Cooper, pp. 41-47; and Foodservice Facts-1998, loc. cit.
} 


\section{Exhibit 1}

\section{Descriptive statistics and correlations for quality ratings and average check}

\begin{tabular}{|c|c|c|c|c|c|c|c|c|}
\hline & Mean & SD & (1) & (2) & (3) & (4) & (5) & (6) \\
\hline (1) Food & 20.86 & 3.18 & 1.00 & & & & & \\
\hline (2) Décor & 18.01 & 4.52 & $.36^{\star \star}$ & 1.00 & & & & \\
\hline (3) Service & 19.14 & 3.05 & $.70^{\star \star \star}$ & $.51^{\star \star \star \star}$ & 1.00 & & & \\
\hline (4) Zagat Top-40 & - & $-.35^{\star *}$ & $.34^{\star \star}$ & $.28^{*}$ & 1.00 & & & \\
\hline (5) Zagat average check & $\$ 42.27$ & $\$ 11.40$ & $.54^{\star \star \star}$ & $.77^{\star \star \star}$ & $.53^{\star \star \star}$ & $.46^{\star \star \star}$ & 1.00 & \\
\hline (6) Operators' average check & $\$ 44.05$ & $\$ 14.93$ & $.53^{\star \star \star *}$ & $.59^{\star \star \star \star}$ & $.52^{\star \star \star}$ & $.39^{\star \star}$ & $.78^{\star \star \star}$ & 1.00 \\
\hline
\end{tabular}

Notes: Two-tailed correlation significance: ${ }^{* \star}=.001 ;{ }^{* \star}=.01 ;{ }^{*}=.05$ level. Food, décor, and service scores are calculated from Zagat Survey 1999. Means and standard deviations were not calculated for top 40, because it is a dichotomous variable. Dollar amounts shown are in Canadian dollars.

tors' reports of check averages are more accurate simply because the operators have direct access to the data to compute the average check. It is reassuring, however, that the consumers' reports closely matched the operators' reports.

With a few exceptions, the restaurants we surveyed were all modest in size. The sample's all-season seating capacity averaged 148 seats, with a range of 36 to 430 seats (standard deviation $=103.11)$. The average weekly sales volume (i.e., dinner covers) reported through our phone survey was 1,913 per week, with a range of 430 to 8,000 . The operators maintained guest-toserver ratios that varied widely. The reported average was 22 guests per server station, but the range was 14 to 45 , with a standard deviation of 7.77 .

\section{What it Takes to Be the Best}

Many restaurateurs use public acclaim as their benchmark of excellence. Such acclaim often comes in the form of a number of stars, diamonds, knives, or forks (depending on the rating organization), or the rating may simply be a numerical score received from customers, as in the case of the Zagat Survey. While each individual operator might have his or her own secret formula for success, little research has attempted to connect restaurant attributes with top ratings-in other words, the "best restaurants." By using the Zagat Survey's top-40 rating as the standard for being the best, we explored this question.

\section{Food, Décor, and Service All Matter}

We tested whether ratings for food, décor, and service were associated with a restaurant's top-40 rating on Zagat's listing. We found that high ratings for food, décor, and service were significantly related to Zagat's top-40 ratings (food, $r=.35, p=$ .01 ; décor, $r=.34, p=.01$; service, $r=.28, p=.05)$. Since both sets of ratings came from the same survey, one might expect a high correlation. However, Zagat's determination of the top-40 rating was based on "top-of-the-mind" recall among its survey participants and not on the food-décor-service scores. Therefore the top- 40 score is statistically independent of the other scores.

One finding that came from this correlation analysis is an unexpectedly low association of service with the top-40 rating. Many researchers (and the conventional wisdom) have focused on service as a key influence to operational success, but food and décor recorded stronger correlations. That finding is further supported by a discussion by Jacqueline Dulen, who highlighted the importance of using ratings on those three factors (i.e., food, décor, and service) 
to increase the accuracy of customers' assessment of a restaurant's quality. ${ }^{10}$

\section{A Top Rating Brings Top Dollars}

Based on our correlational analyses, we noted a strong, positive association between a top-40 rating and the average dinner check in both the Zagat Survey and telephone surveys. Zagat's dinner-check averages showed a slightly higher correlation with the top-40 ratings ( $r=$ $.46, p=.01)$ than with the data provided by the restaurant managers $(r=.39, \mathrm{p}=.01)$. That finding suggests that when customers think highly of a restaurant (for example, by giving it a top rating), check averages are likely to be higher than otherwise. High average checks were also associated with favorable ratings on food, décor, and service. ${ }^{11}$

We can see, therefore, that four elements contribute to the top-40 restaurants' ability to command a menu premium. It comes as no surprise that restaurants seeking high average checks must offer good food, maintain a pleasing setting, and provide good service. Beyond that, however, strong overall ratings also help buoy menu prices. Those findings are consistent with research reported by Cotter and Snyder. In two separate studies they found that high ratings from the Mobil and Michelin travel guides helped drive menu prices. ${ }^{12}$ However, their studies focused primarily on food qual-

\footnotetext{
${ }^{10}$ Jacqueline Dulen, “Quality Control," Restaurants E Institutions, Vol. 109, No. 5 (February 15, 1999), pp. 38-52.

${ }^{11}$ For the Zagat rating, food $r=.54, p=.01$; décor $r=.77, p=.01$, and service $r=.53$, $p=.05$. For the operators' reported check averages, food $r=.53, p=.01$; décor $r=.59$, $p=.01$, and service $r=.51, p=.05$.

${ }^{12}$ See: Michael J.Cotter and Wayne Snyder,

"How Mobil Stars Affect Restaurant Pricing Behavior," Cornell Hotel and Restaurant Administration Quarterly, Vol. 37, No. 2 (April 1996), pp. 34-41; and Wayne Snyder and Michael Cotter, "The Michelin Guide and Restaurant Pricing Strategies," Journal of Restaurant \& Foodservice Marketing, Vol. 3, No. 1 (1998), pp. 51-67.
}

ity, with little emphasis on décor and service. Our findings indicated that there was indeed more to good ratings than just the food alone, as shown in Exhibit 1.

\section{Attributes That Mattered Most}

The term "amenities" seems to be associated more with the hotel industry than with the restaurant industry. Marketing researchers tell us how chain hotels use amenities to differentiate their products, segment their markets, target specific users, add value to their brands, and build brand equity. Ultimately, when a particular set of amenities is chosen and appropriately offered, its revenue-generating potential is apparent. ${ }^{13}$

Applying this logic to the restaurant industry we asked, "Would certain amenities - often taken for granted by restaurateurs and consumers-have a direct impact on average check?" We use the word amenities in a broader sense than might apply to the hotel industry by examining features that are appealing or that augment comfort.

Toronto Life's restaurant and menu listing provided us with data to help answer the above question. Toronto Life provided information on ten different amenities or services present (or absent) in each listed restaurant. In Exhibit 2 we present a frequency breakdown of the amenities offered in our sample of restaurants. We follow the frequency analyses with a set of three regression analyses to examine the influence of the amenities on the Zagat Survey's ratings of food, décor, and service.

\section{Three Common Attributes}

The three amenities most frequently offered by our sample of restaurants were a smoking section (81 per-

\footnotetext{
${ }^{13}$ Jeanine Carey, "Amenities Take On New Role as Profit Generators," Hotel Business, Vol. 7, No. 21 (November 7-20, 1998), pp. 82-83.
}

\section{Exhibit 2 \\ Listing of restaurant amenities in Toronto Life magazine $(N=63)$}

\begin{tabular}{lc} 
Amenity & $\begin{array}{c}\text { Number of } \\
\text { restaurants }\end{array}$ \\
\cline { 2 - 2 } Acceptance of credit cards & 63 \\
Smoking section & 51 \\
\hline Catering services & 40 \\
Takeout services & 34 \\
\hline Dress code & 32 \\
Parking & 28 \\
\hline Seasonal outside seating & 27 \\
Web site or e-mail address & 17 \\
\hline Late-night dining & 9 \\
Live entertainment & 4 \\
\hline
\end{tabular}


cent), catering (63 percent), and take-out (54 percent). Since the restaurants we examined all accepted at least a few credit cards, we considered that attribute to be a constant and excluded it from the regression analyses. Although not listed as an amenity by Toronto Life, all the operations we surveyed also reported that they offered full bar service (i.e., beer, wine, and spirits). smoking available. We found it intriguing that the restaurants we examined continued to offer smoking sections, given what appears to be a trend toward a full-fledged ban on smoking in public areas-and the City of Toronto's own legislation that greatly limits smoking in restaurants and bars. We have no direct data on this matter and can only speculate. Owners may fear the kind of losses initially experienced by California's restaurant industry when that state instituted a smoking ban. ${ }^{14}$ Alternatively, owners could also point to the fact that we have yet to sufficiently quantify the effects of smoking bans on restaurant patronage, as noted in 1998 by Mogelonsky. ${ }^{15}$ Finally, the continued (albeit dwindling) cigar-smoking trend might have given restaurateurs sufficient reason to keep this oftencontroversial option available to their patrons. ${ }^{16}$

Catering. Catering offers a restaurant operator the chance to build the bottom line by expanding sales and service beyond the physical constraints of the building - much as banquet sales do in hotel food service. More than half of the restaurants in our sample provided this service for their patrons, indicating that the operators recognize

\footnotetext{
${ }^{14}$ See: John Doyle, "Insights into the Californian Restaurant 'Crash,'” Nation's Restaurant News, Vol. 32, No. 30 (July 27, 1998), p. 6.

${ }^{15}$ Marcia Mogelonsky, "Non-Smoking or

Non-Smoking?," American Demographics, Vol. 20

No. 8, (August 1998), pp. 56-57.

16 "Cigars," Cheers, Vol. 9, No. 9 (November/

December 1998 Supplement), pp. 23-24.
}

catering's financial and promotional potential.

Take-out. Take-out service also seemed to be important to operators in our sample. Indeed, the growing market share of home-meal replacement constitutes a "significant growth opportunity" for restaurateurs, as suggested by Ron Paul of Technomic. ${ }^{17}$ Therefore, it is not surprising that a large portion of our respondents offer take-out service to their patrons. Our findings echo Paul's comments. That is, operators are not treating the takeout business as an afterthought anymore.

\section{Three Attributes of Interest}

Three features or amenities were not offered universally in our sample, but still showed a relatively strong presence. We found dress codes in place in half of the restaurants (out of 63 total), and parking available in 28 of those restaurants and outside dining available in 27.

Dress code. First, we assumed that if a restaurant had a dress code in place, that code was consistently enforced. Second, we recognized that the overall dining scene is becoming increasingly casual over time. Even the $21 \mathrm{Club}$ in New York City has begun to ease up on its dress code, and other operators are quickly following suit (so to speak). ${ }^{18}$ Despite recent trends to move away from relatively formal dining settings in full-service restaurants, we suspect that a dress code promotes a high-level image for a restaurant - an image that would foster strong menu prices.

Parking. As is the case in most metropolitan areas, parking in

\footnotetext{
${ }^{17}$ As quoted in: Nancy Brumback, "Replacement Parts," Restaurant Business, Vol. 98, No. 11 (June 1, 1999), pp. 49-52.

${ }^{18}$ Milford Prewitt, "Ties No Longer Binding: '21' Club Eases Dress Code Permanently,' Nation's Restaurant News, Vol. 31, No. 6 (February 10, 1997), p. 6; and Margaret Sheridan, "Service to a Tee," Restaurants E Institutions, Vol. 108, No. 11 (May 1, 1998), pp. 109-116.
} 
Toronto can be a challenge. The availability of parking facilities on site or nearby is likely to help a restaurant attract guests, particularly those who would drive in from the suburbs or from out of town. Moreover, patrons who are not familiar with or do not have direct access to public transportation in the city will certainly appreciate convenient access to parking.

Outside dining. Having a patio or open-air seating provides additional revenue opportunities to operators during the warm months. Additionally, open-air dining is likely to enhance the ambience of a dining experience. In metropolitan areas, however, this amenity may not be easy to offer due to space constraints or zoning restrictions.

\section{Three Uncommon Attributes}

We noted three amenities that few full-service restaurants offered. Only 17 restaurants had a presence on the internet through either a web page or an e-mail address; just nine of the restaurants offered a late-night menu; and only four of the restaurants offered some form of entertainment, such as music, dancing, theatre, or comedy.

Internet presence. We expect to see an increasing number of restaurants go on-line as the internet continues to gain a strong presence among consumers. Seventeen of 63 restaurants in our sample is a modest showing for this feature, especially given how completely hotels and travel-related companies have embraced on-line operation. Our findings, however, echo those of a 1999 report by Durocher on internet use by restaurateurs. ${ }^{19}$ Other studiesincluding one conducted by the National Restaurant Association in 1998- have shown that restaura-

\footnotetext{
${ }^{19}$ Joseph Durocher, "Net Profits," Restaurant Business, Vol. 98, No. 10 (May 15, 1999), pp. 149-150.
}

teurs' absence from the internet may reflect a market reality. So far, diners tend not to use the internet to gather information about dining options and restaurant services. ${ }^{20}$ On the other hand, that phenomenon may simply arise from the fact that would-be diners have found so little restaurant information on-line.

Late-night menu. A light, latenight menu is often a popular offering among restaurants in metropolitan areas. Late-night service can appeal to people who have attended the theatre or those who plan to enjoy the nightlife in clubs following a meal. Late-night food service often draws a slightly different clientele than does the traditional dinner meal period. Typically, the late crowd is more interested in the bar trade than are early diners. Given our sample of relatively traditional full-service restaurants, we are not surprised that only a few of them offered late-night fare to their guests or that most operated just during the traditional dinner hours.

Entertainment. Along the same lines, our sample of traditional-style restaurants was not in the "eatertainment" business. Toronto certainly has had such concepts (notably, the Organ Grinder), but the types of entertainment classified by Toronto Life (e.g., comedy, live music, theatre) seemed to be geared to a market different from that of the typical full-service restaurant.

\section{Amenities That Count}

To determine which of the nine amenities described above were most influential on consumers' perceptions of their dining experience, we examined their influence on the food, décor, and service ratings re-

\footnotetext{
${ }^{20}$ See: Tableservice Restaurant Trends-1998 (Washington, DC: National Restaurant Association, 1998), pp. 29-34; and Tony Seideman, "Internet Marketing-How Restaurateurs Break Through the Hype," Market Watch, Vol. 17, No. 2 (March-April 1998), pp. 90-93.
}

\section{We expect to see more}

restaurants go on-line as

the internet continues to gain

a strong presence among

consumers. 


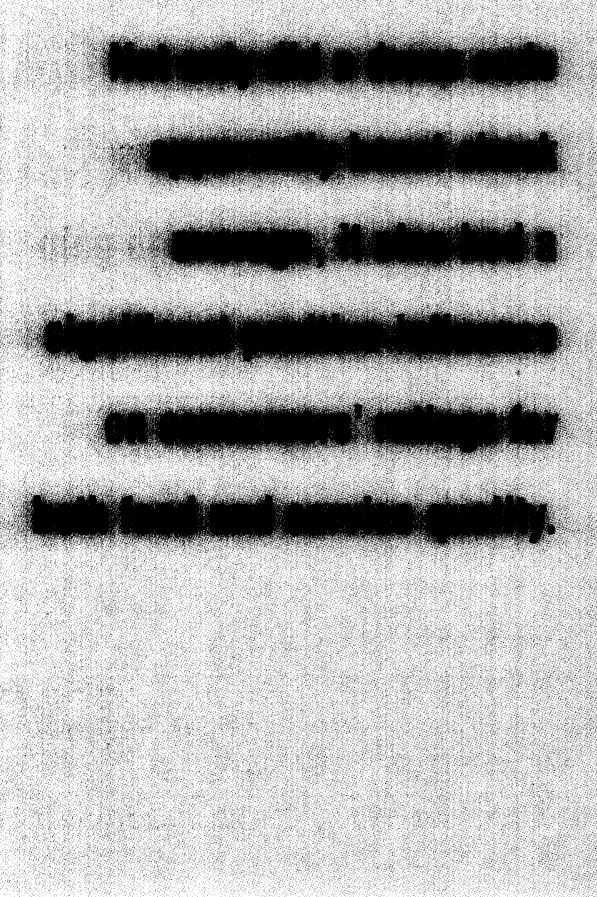

ported by the Zagat Survey. As noted above, because credit cards were accepted in all of the establishments that we examined, we excluded that variable from the analyses.

Food and service ratings. In regression analyses, two of the nine restaurant features demonstrated a positive influence on the guests' perceptions of both food-quality and service ratings. First, the presence of a dress code was a significant influence on the ratings for both food and service quality. ${ }^{21}$ That is a puzzling outcome. We did not believe that a dress-code policy would directly affect patrons' perceptions of a restaurant's food or service quality. A possible explanation for this curious finding is that most restaurants with dress-code policies tend to be upscale and should by definition offer top-quality food and service.

The second attribute that influenced consumers' perceptions of food quality and service quality was the presence of a late-night menubut this was a negative effect in both cases. That is, for our sample the existence of late-night food service reduced perceptions of food and service quality. ${ }^{22}$ We believe that the late-night fare is likely reaching a different market than the one that contributes to the Zagat ratings. We speculate that those who do contribute to Zagat might associate latenight menus with night spots that are noisy or somehow undesirable.

The dress-code and late-nightmenu factors combined in the regression equations to produce a multiple $R$ of .52, and an $R^{2}$ of .27 . This means that the two together explain 27 percent of the variance in the consumers' ratings of food quality. In the same fashion, the combined influence of the dress-code and late-night-menu amenities on

\footnotetext{
${ }^{21}$ Food: $\beta=.26, p=.05$ service: $\beta=.38, p=.01$

${ }^{22}$ Food: $\beta=-.42, p=.002$; service: $\beta=-.44, p=.001$.
}

service quality produced a multiple $R$ of .59, and an $R^{2}$ of .35, explaining 35 percent of the variance in the consumers' ratings of service quality.

Amenities driving décor ratings. Two amenities, having a dress code and offering take-out service, influenced décor ratings. The connection between dress code and décor again is the likelihood that a dress code helps to maintain a formal atmosphere $(\beta=.43, p<.001)$. On the other hand, take-out service seemed to spoil the décor for some guests, as the regression relationship between offering takeout service and gaining a high décor rating was negative $(\beta=-.40, p=.001)$.

We think it likely that the additional traffic and commotion that can accompany the takeout process creates negative perceptions for guests, especially those waiting to be seated in a busy restaurant. Some restaurant companies (e.g., Outback Steakhouse) avoid this problem by maintaining separate entrances or waiting areas for their takeout guests. In our survey, the dress code and take-out service amenities combined produced a multiple $R$ of .69 , and an $R^{2}$ of .47 . Thus, they explained 47 percent of the variance in the consumers' ratings of the restaurants' décor.

\section{Influences on Check Averages}

Testing the influence of our nine features and amenities on check averages, we discovered three notable influences. One of those is the connection between a dress code and an increased average check $(\beta=.38, p=.004)$. As we noted above, this effect is likely due to the fact that most restaurants with a dress code are generally upscale. Does this mean, though, that restaurateurs should implement dress codes? It does run against the trend toward casual dress, but we suggest that if a restaurant concept is suited to a dress code a restaurateur should 
at least consider such a policy, especially given a dress code's apparent positive influence on our restaurants' Zagat rating for food, service, and décor.

The presence of takeout service was noted as a significant negative influence on average check $(\boldsymbol{\beta}=$ $-.26, p=.05)$. This finding suggests that takeout might actually lower check averages - most likely in part because takeout orders are less subject to in-store merchandising and are less likely to include a beverage, appetizer, or dessert (all of which boost check averages). In this instance, however, average check may not be the correct gauge of the success of this business feature. Most operators find that takeout improves the bottom line, owing to takeout's low cost structure relative to full dining-room service. Thus, even if per-transaction revenue (average check) is not as high for takeout as it is for sit-down diners, the restaurant may still benefit from offering takeout. If full-service restaurateurs truly want to examine the effects of takeout on their business, they should emulate quick-service operators' method of closely monitoring dinein, drive-through, and carryout sales.

Finally, offering parking was noted as having a significantly positive relationship on average check $(\beta=.27, p=.02)$, indicating that providing parking to guests may improve check averages. As noted earlier, this finding must be interpreted in light of the difficulty of parking in large cities like Toronto. Apparently operators who either provide parking directly themselves or contract for parking services are able to command a higher average check. While this effect might not hold in suburban locations where all players usually offer adequate parking, we think metropolitan operators should not overlook this amenity. Taken together, dress code, takeout service, and parking produced a multiple $R$ of .60 , and an $R^{2}$ of .37 , explaining 37 percent of the variance in the reported average check.

\section{Practical Implications}

While not all of the factors we examined here led to statistically significant outcomes, each factor we examined clearly had some influence in the customers' assessment of service quality. As demonstrated by Zagat's three-pronged rating approach, food quality remains a key factor, but it ranks in the consumer's mind alongside fine service and a pleasing environment. All three of those factors were related to Zagat's top-40 ratings and to check averages in this study.

Second, certain restaurant attributes may turn out to be doubleedged swords. In particular, offering takeout service and late-night dining appeared negatively to influence ratings and check averages in our sample of full-service restaurants, even though both of those attributes may help the restaurant's bottom line. While the meal-replacement business has in general been growing strongly, our analyses indicate that takeout was a negative influence on the operations we examined. Our methodology did not include an investigation of why that might be so. Thus, we caution operators to carefully consider how they implement takeout service and what effect it has on their dine-in guests. As with so many services, poorly handled takeout may be worse than none at all. Outback's separate (and seamless) approach allows guests simply to drive up to the store to take away their food order. We recognize that space constraints associated with metropolitan locations may limit what can be done in this arena. Some amenities, particularly those that are offered with moderate frequency (e.g., outside dining and parking), may well add to a restaurant's competitive advantage.
It also appears that restaurant operators need to try to catch up with current technology. It is only a matter of time before web-based commerce grabs a strong foothold in the restaurant business. Food-service operators now have on-line opportunities for not only business-toconsumer services, such as menu posting and reservation services, but also business-to-business opportunities, such as Zoho.com, Sauce.com, or BevAccess.com, where operators can get involved with procurement and receive on-line consulting services at the click of a mouse.

In conclusion, this study provides restaurateurs with a quantitative methodology to examine their market and competitors. Most major markets have a number of sources for restaurateurs to collect consumer ratings (e.g., Zagat Survey) and thirdparty ratings (e.g., Mobil Guide, Michelin Guide). With the addition of operator data from the restaurateurs themselves or sources such as Toronto Life, one can take a critical look at market performance beyond the profit-and-loss statement.

In this study, we did not break up the sample geographically or by cuisine type or style, but we could have. Individual operators should examine those factors against their specific competitive set. Such an analysis should indicate how a particular restaurant operation compares to its competitive set and what amenities the restaurant might add (or drop) to raise its standing with customers. For example, if a restaurateur identifies that parking is a significant influence on average check, it would be worth examining the costs and benefits of including some sort of parking service to meet the guests' needs. Restaurant operators should consider these issues seriously and monitor their own market carefully to ensure that their offerings are consistent with market demand and supply. CQ 